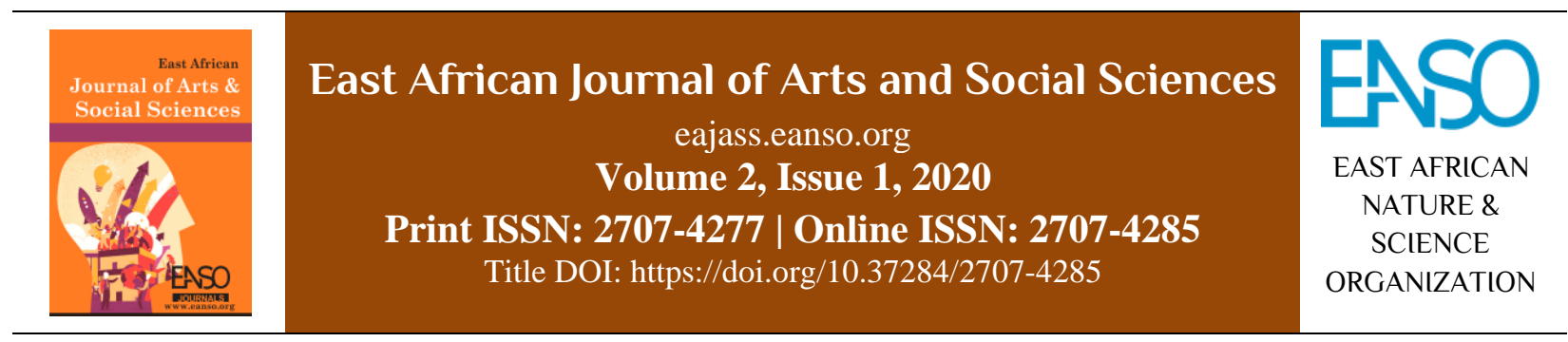

Original Article

\title{
'The Soul of my Sculptures' - A Contemplative Analysis of The Work of Naftal Mageto Momanyi
}

\author{
Dr. Kamau Wango, $P h D^{1 *}$ \\ ${ }^{1}$ Kenyatta University, P. O. Box 43844 - 00100, Nairobi, Kenya; ORCID: https://orcid.org/0000-0002-0185-1355. \\ *Author for Correspondence email: kamauwango@gmail.com.
}

Article DOI: https://doi.org/10.37284/eajass.2.1.218

\section{Article history: ABSTRACT}

30 September 2020

Keywords:

Creative selfexpression,

Subconscious

Phenomenon,

Interpretive Expression.
Despite the significant resurgence of expressive creativity through works of art in various disciplines particularly painting and sculpture, the underlying inspiration and subsequent endeavour for self-expression by artists, be it derived from experiences, observation of events and occurrences, imaginative compositions or even from the subconscious mind or surrealism, is often not very well articulated among the artistic audience or general public. This is in view of the general consensus among creative artists that works of Art are composed or created to be inherently expressive of something and hence should be given the opportunity to be seen and appreciated. It has been observed that often the artistic audience or general public only superficially examine the works of art in passing without necessarily delving into the expressive essence of the work itself. Hence the genesis of the expression, thought patterns or the philosophical foundation that underscore an artist's inspiration and subsequent creation of that work is therefore just as often missed. If any work of art is not accorded adequate exposure and does not receive a fair amount of interrogation in terms of its creative and expressive substance or in terms of its contribution to the development of style, technique and application of materials, then that artwork runs the risk of being redundant. In addition, if this interrogation is not brought to the attention of the relevant artistic audience or articulated to the general public through exhibitions, relevant artistic fora, such as seminars, workshops and conferences, then the work amounts to a missed opportunity of its original purpose. There has been of course the debate about the nature and extent of participation by the 'audience' including the public and whether this audience bears the prerequisite qualification to interrogate or critique works of art including sculptural pieces. This paper does not, however, deal with this 
particular query. The focus of this paper is to demonstrate that sculptures are not mere embellishments but are a fundamental tool for commentary about pertinent societal issues in selected areas of endeavour. They, therefore, epitomize the artist's point of view (POV) or opinion that underscores his or her sense of individual self-expression and hence lends credence to each piece. The paper, therefore, examines firstly, the origins of African sculptural tradition and the development of self-expression as a key tenet of form/content appreciation; and secondly the purposeful derivation of ideas from broad themes as well as the composition of specific subject matter as an avenue for the sculptor to address the retinue of societal issues. The paper covers six sculptural pieces seen from different angles created by Naftal Mageto Momanyi, a prominent Kenyan sculptor who works mainly using granite, wood and soapstone.

\begin{abstract}
APA CITATION
Wango, K. (2020). 'The Soul of my Sculptures' - A Contemplative Analysis of The Work of Naftal Mageto Momanyi. East African Journal of Arts and Social Sciences, 2(1), 116-133. https://doi.org/10.37284/eajass.2.1.218
\end{abstract}

\title{
CHICAGO CITATION
}

Wango, Kamau. 2020. “The Soul of my Sculptures' - A Contemplative Analysis of The Work of Naftal Mageto Momanyi”. East African Journal of Arts and Social Sciences 2 (1), 116-133. https://doi.org/10.37284/eajass.2.1.218.

\section{HARVARD CITATION}

Wango, K. (2020) “"The Soul of my Sculptures' - A Contemplative Analysis of The Work of Naftal Mageto Momanyi”, East African Journal of Arts and Social Sciences, 2(1), pp. 116-133. doi: 10.37284/eajass.2.1.218.

\section{IEEE CITATION}

K. Wango, “The Soul of my Sculptures' - A Contemplative Analysis of The Work of Naftal Mageto Momanyi”, EAJASS, vol. 2, no. 1, pp. 116-133, Sep. 2020.

\section{MLA CITATION}

Wango, Kamau. “The Soul of my Sculptures' - A Contemplative Analysis of The Work of Naftal Mageto Momanyi”. East African Journal of Arts and Social Sciences, Vol. 2, no. 1, September 2020, pp. 116-133, doi:10.37284/eajass.2.1.218.

\section{INTRODUCTION}

Sculptural work, particularly selected individual pieces or compositional forms that have been grouped together to emanate a desired message, has always been instrumental in the derivation of ideas and thought as well as serving as commentary on various matters affecting society. Indeed, the principal objective of any sculptural work within the realm of self-expression is not only to depict artistic creativity or individual skill but more importantly, to elicit some kind of thoughtful response or spur conversation that helps to draw and focus attention upon the particular subject matter. This is regarded as the appreciation of content beyond the composition or creativity of form itself. It is of course difficult to separate the two since they have a symbiotic relationship. It is, however, the desire of any sculptor and Artist in general to create work which would ultimately spark appropriate debate on a given subject matter and perhaps become a catalyst for social discourse and subsequent change. As an integral part of the Fine Arts, sculpture has been a critical platform in which the primary concern in the production of work is to showcase work that is holistically creative, undoubtedly imaginative and aesthetical in its form, as well as drawing upon a significant degree of intellect in the interrogation of content or subject matter. In Kenya, sculpture has over the years played a significant and admirable role in this regard, particularly in the quest towards selfexpression by various sculptors, but the level of 
artistic appreciation has not always been commensurate with the potential therein. This study posits that the first level of appreciation of any sculptural work in particular, and any Artwork in general, is basically the descriptive first impression; whether it artistically strikes the eye in terms of general execution and application of materials as well as the overt perception it elicits. What does the audience immediately or instinctively derive from it in their first encounter? This is followed by the more interrogative search for its imaginative and aesthetic value; how does the sculptor interweave elements and principles of Art in the composition and description of form? Finally, the content itself is interrogated; what is the core content of the work and what is indeed the ultimate message? This 'core content' may be purely descriptive of a specific situation, or lamentation of a given injustice or it may be embedded in or intertwined with a given degree of intellectual discourse in which case the sculpture itself may take a little thoughtfulness to unravel and hence appreciate. It is this interrogation of content that this paper draws particular interest since it has often tended to be relegated to the periphery as people take more interest in the formal analysis.

All these levels of appreciation require a significant amount of focus by the respective audiences and with the significant resurgence of sculptural work in Kenya, it is imperative that the given audience and the general public, perhaps through sensitization, begin to recognize in earnest the unique role that sculptors play in highlighting pertinent matters that affect society. In this regard, viewing, appreciating and interrogating their work is important in the understanding of these social matters be they social/political, social/economic, social/cultural, religious or others as the case may be.

\section{Sculpture as a facilitator to creativity and self- expression}

Within the realm of the Fine Arts, sculpture alongside painting stands out to be arguably the most influential disciplines used by artists as avenues for creative self-expression in contemporary times.

The term 'creative self-expression' is key in the context of this paper as it refers specifically to the unique ability of the individual artist to utilize his/her creativity in producing a work of art that bears aesthetic purpose (creative mind) and more importantly, to delve into individual interpretation of a given subject matter through the application of a thoughtful/analytical process (intellectual mind). This first stratum of creative self-expression, therefore, emanates from a mind that is not only just creative but endowed with the necessary wherewithal to dissect pertinent issues, observe events and occurrences, interpret complex societal matters and ultimately generate an informed opinion' that is presented aesthetically and hence can be viewed, appreciated and enjoyed by the general audience. In this case, the artist is viewed as an 'opinion leader' whose creative work seeks to highlight certain pertinent issues in society be they social/cultural, social/political, social/economic, religious or any other matter of social interest. The intended result of this is to draw attention upon the particular issue in focus and spur the kind of response and action that leads to practical remedies and solutions. The second stratum of 'creative selfexpression' encompasses what can be referred to as the 'subconscious phenomenon'. This phenomenon embedded in the sub-conscious mental dispensation, allows the artist to retreat, as it were, into the subconscious world where reality as it exists in the conscious world, ceases to manifest itself and is replaced by the sub-real, the bizarre, the surreal or the purely blissful as embedded in dreams and fantasies. This allows the artist to generate his/her own ideas and express feelings and emotions that are unique to his/her own mental 
experiences which are intertwined with his/her own individualism. Since this mental activity is unique to a particular artist, it translates to what has often been referred to as subjectivism. In both strata, creative self-expression is therefore accepted to be essentially subjective.

Sculpture as a discipline of the Fine Arts has been used since time immemorial as a vehicle for aesthetic creativity through the exploration of various types of materials. In order to put into perspective the role of sculpture as a facilitator to creativity and self-expression, it is prudent to examine briefly the transition of African sculptural tradition from traditional society to contemporary times. The earliest form of African sculptural tradition was found in Northern Nigeria in the village of Nok (the holistic presentation of which is often referred to as 'Nok culture'), as well as other parts of Nigeria where the sculptures included pottery heads, clay figures, bronze bowls, bronze heads and sophisticated stone heads from Northern Yorubaland. As observed earlier, the role of the sculptor in the traditional Nigerian society, for instance, was not for purposes of self-expression but for communal service. Sculptors and other cadres of craftsmen were trained through a traditional method of apprenticeship and were hence not exposed to any kind of formal training. At times referred to as 'Tribal Art', traditional art focused on the 'tribe' as the source of inspiration for the execution of all art, including sculpture and hence artists and craftspeople were not inclined towards expressing their own personal ideas or feelings or the content of their personality as we see sculptors and other artists do today, or as it was understood in the modern European context. Fagg (1963) notes that:

Tribe is an exclusive group, which uses Art among other means to express its internal solidarity and self-sufficiency and conversely its difference from all others. Traditional art belongs to the tribe, which uses it to express their beliefs, aspirations, and hopes in life (p.7)
Sculpture, in particular, was therefore important as an expressive tool in traditional African societies although it can be argued that the purpose of African sculptural tradition in those African societies was not necessarily for self-expression but was mainly for community service and hence served a specific secular, ceremonial or religious purpose. However, upon the onset of the Europeans in Nigeria, the white missionaries endeavoured to downplay the essence of African artistic tradition by actively and methodically undermining the beliefs, traditions and social structures that formed their inspiration. Mbahi (2003) notes:

\section{Traditional art was particularly looked upon with disfavour and as a hindrance to Christian evangelism and conversion. There was widespread evidence of direct and deliberate attempts to destroy or suppress indigenous Arts and attendant ceremonies that inspired their creation (p. 36)}

To help clarify the origins of self-expression as a specific endeavour by African sculptors and other artists within the realm of the new or modern Art, Beier (1961) identifies and categorizes the emergence of three generalized groups of African artists in Nigeria. The first category comprised of artists who were inclined towards retaining the traditional art in the midst of the changing contemporary environment by adapting, developing and aligning traditional art to modern conditions, as well as experimenting with new materials. They were by and large locally trained through established apprenticeship systems. The second group comprised of artists who sought to break away from traditional art altogether and wanted to embrace foreign techniques and styles and were therefore fascinated by the artistic tenets of European Art. This group sought training opportunities in Europe, particularly France and Britain. The third group comprised of artists who derived little interest in the defined conflict between traditional art forms and modern European techniques and were more interested in developing 
a personalized approach to solving problems, a major departure from the traditional art where art forms were inspired by traditional culture, believes and traditions which ultimately served the interest of the community or tribe.

It is the third group that draws the interest of this paper since it clearly marks a turning point in the emergence of the concept of 'self-expression' as an integral part of how artists viewed their role in the contemporary dispensation. On this development, Beier (1961) further describes the work of the artists:

Their work is very individual.... the Artists are grappling with ideas, with psychological and cultural problems. Their pictures are heavy with content and charged with emotion. Somehow a definite tendency toward expressionism (p. 31)

\section{Exploration of sculptural themes and generation of subject-matter for public consumption}

Expressive Sculptural work is by and large done for the primary or sole purpose of communicating a message to an audience, be they a specified or selected audience or the general public. Hence a sculptor embarks on a creative piece with the intension or purpose of expressing a considered point of view or a rationalized opinion. But for clarity, it is useful to comprehend this matter from two broad perspectives that constitute the background of the development of sculpture and its application in society; firstly, the execution of sculpture in the traditional dispensation and, secondly, its execution in the modern dispensation.

As has been already stated, the execution of sculpture in the African sculptural tradition was for the specific purpose of serving the community, particularly in such endeavours as the enhancement of religious traditions and beliefs seen, for instance, in the pacification and influencing the world of spirits; it has been observed that Yoruba ancestral sculptures, particularly carvings in shrines, were meant for the honour of spirits worshipped (Mbahi, 2003). Sculptures also served the secular purpose; such as architectural/sculptural productions and decorations as well as other related forms such as household furnishings. The production of sculptures also served a ceremonial purpose that enhanced social structures including hierarchical authority such as that of Kings and Chiefs complete with the carvings of many aspects of their royal insignia. Contrary to the modernist approach to sculptural production, African sculptural tradition had little to do with 'self-expression' as it is understood today. The modernist approach, signified by the onset of European influence in northern Nigeria, for instance, encompassed the concept of 'self-expression' where there was a strong tendency towards the exploration of ideas, content and emotions, laced with strong individuality.

In the context of this paper, therefore, the examination of the role of themes in the generation of the subject matter will be confined to the concept of 'self-expression'. The need for self-expression emanates from the 'urge' or 'need' to create a work of art based on a given motivation that acts as a catalyst. This catalyst may emanate firstly from one's feelings, emotions, desires and other psychological phenomena that captivate human imagination. This catalyst then crystallizes, through imaginative thought processes into a creative product that can be expressed and viewed as a work of art, in this case, though sculpture. Secondly, this catalyst may also emanate from certain broad themes that cover human endeavour from which a sculptor generates specific subject matter. In this case, sculptors and artists in general, respond to given themes as their motivation to address a specific human phenomenon, challenge or opportunity from which they derive appropriate subject matter. Their response to themes, therefore, translates into artistic interpretations of the embedded key thematic elements that help to inform and construct the resultant creative work. By 
this, the sculptors themselves derive their subjective interpretation and formulate their individual opinion that helps to influence the specific audience, community or general public.

Most of the more often explored thematic considerations emanate from activities, attitudes and prejudices; cultural and traditional believes and practices; social/economic and political decisions; events and occurrences (historical or current) which constantly affect and/or influence the wellbeing of people in any society and at any given point in time. It must be emphasized that in tackling these themes and in developing subject matter, and for the final work to project a certain level of dynamism, the artist here is considered to be an originator of purposeful thought and hence a generator of opinion. The artist is expected to possess a viable level of intellect and generate the necessary insight to enable him/her navigate thematic undercurrents. The artist in this case should possess the attributes of a thinker, aesthetician and philosopher. (Borrowed from Peligah, 2003). The special place of all expressive Art, including sculpture in becoming a significant catalyst for enlightenment and positive action is summed up by FriendenwaldFishman (2011)

There is no discipline that nurtures and sparks the cognitive ability to imagine and unleashes creativity and innovation, more than arts and culture. There is no approach that breaks barriers, connects across cultural differences, and engages our shared values more than arts and culture. There is no investment that connects us to each other, moves us to action, and strengthens our ability to make collective choices more than arts and culture (p.2)

Some of the broad thematic categories from which artists draw their inspiration and seek to participate in addressing various issues are:

\section{Social/economic}

Social/economic themes have dominated artistic expression and creativity for long periods in history. This is because the functional value and wellbeing of any society and all human endeavour is intertwined with and ultimately calibrated through social/economic parameters. Artists have explored social/economic themes in order to draw attention particularly to imbalances, inequalities and injustices that constantly plague communities and societies the world over.

\section{Political}

Political decisions, events and occurrences have often been so profound and have been critical either in determining the general wellbeing of societies or have been the root-cause of upheavals and prolonged human suffering at various points in history. Through creative interpretive expression, artists have always had a unique role to play in the interrogation of political themes that have in turn played a key role in public enlightenment and agitation for just societies.

\section{Social/Cultural}

Social/cultural themes in this paper refer to all the social and cultural dynamics that are embedded in the functioning of any society. Artists have been particularly keen on social dynamics and their general implication in specific societies across time and how those societies, subsequently, have attained their equilibrium, sustainability and survival. Very intricately intertwined with these, are cultural norms and practices that define the soul of any given society. Artists have been equally keen on examining cultural and traditional themes seen through numerous artistic pieces throughout history.

\section{Historical prejudices}

Historical prejudices are very broad and often transcend many facets of human interaction. Some 
of the most infamous include religious, racial, ethnic, hierarchical, social structural, economic, wealth distribution and ownership, and cultural prejudices among others. But since prejudices are fundamentally negative phenomena that have occurred throughout human history, artists have been constantly engaged in addressing these prejudices whenever they have manifested themselves, with the purpose of instigating public awareness and spurring the necessary sensitization leading to interventions that have helped alleviate them.

\section{Spiritual/religious}

Spiritual and religious matters play a significant role in thematic interpretation and construction of subject matter by artists. In African traditional societies, the honour and pacification of ancestors was a critical intermediary in communication with the spirit world. Sculpture was used as an avenue for the honour of the spirits and influencing their world. Sculpture was also used for the production of traditional ritual forms such as masks and certain figures for religious ceremonial worship. Mbahi (2003) observes that:

These objects help the worshippers to experience the nature and presence of their Gods by providing an image to which they can relate and experience jointly and communally (p.35)

In the modern dispensation where self-expression or general thematic based expression takes centre stage, artists now grapple with spiritual and religious themes since spirituality and religion still form the core of how communities function and sustain their collective sense of purpose. Artists have, for instance, often expressed through their creative work, their opposition to forms of religious persecution and exclusivity wherever they have occurred. They have also used their creativity in the exaltation of supreme power that emanates from God as contained in religious doctrine.

\section{Popular culture}

Popular culture forms an integral part of how artists respond to contemporary themes since it encompasses trends, practices, beliefs and peculiarities that are consistent and aligned with a particular society within a given point in time. Since the scope of popular culture is so wide, the artist often utilizes the power and influence of aspects of this popular culture by embedding in his/her work aspects that are easily recognizable and carry certain truths. This is particularly important in the expression of any opinion that is aimed at the youth.

\section{The artists self-view of his sources of inspiration}

In examining the work of Naftal Momanyi, one builds a clear impression of a confluence of sources of inspiration. Each of his pieces can therefore be seen to be as a result of either multi-inspirations or a particular given source of inspiration. On one hand, therefore, he posits that his inspiration is derived from the desire towards self-expression, which includes emotional experiences, ideas and personified thoughts. On the other hand, he asserts that he is also inspired by the need for social commentary through interpretive analysis of topical themes which are then expressed artistically. In commenting about self- expression, he states that:

The inspiration for my art springs from the compelling desire to communicate my emotional experiences to the people using artistic imagery based on topical themes.

In describing this aspect of his work, he states that:

Though my sculptures are carved in diverse techniques, the basic bond that unites them is the beauty and the intensity of their emotional content.

He asserts on the other hand that he is also inspired by the need for social commentary through interpretive analysis of topical themes which are 
then expressed artistically. In such instances, the Artist becomes an observer of events and occurrences and is able to derive the profoundness of such events and occurrences and convert them to visual interpretation that the public can view and appreciate. In other instances, the Artist becomes an opinion leader or problem-solver after applying some measure of analytical thought or a dissective approach to a given situation or pertinent matter affecting society. He further asserts therefore that:

Art provides a great opportunity for me to reflect on our cultural consciousness as a people. I create art not only to express myself but also to commentate on issues I consider useful to society.

For purposes of understanding his work he attempts to distinguish somewhat between 'self-expression' and 'social commentary'. He emphasizes that 'selfexpression' must be seen as emanating from the subtle 'self' such as may be derived from the images that form and flow in one's mind which are purely individual and are a reflection of internal impulses. He explains that 'social commentary' on the other hand involves the application of the analytical mind that helps to draw interpretive conclusions on pertinent or emerging social issues. He emphasizes the term 'interpretive ability' meaning that for the artist to be able to express something of significance through artwork, he or she must have the ability to study and analyze, dissect or unravel an issue at hand and hence come up with an interpretation that is visual yet still personal. This in turn culminates in the derivation of subject matter that emanates from and responds to that issue. In this regard, the artist is able to compose a piece of Art that integrates adequate information and the hallmarks of his or her individualism. The sculptor notes that:

I have always been interested in that which lies hidden or lodged between our understanding of our own identity and the world around us; through visualization, I explore in depth the intricacies of diverse human characteristics using sculpture.

Using an abstract approach to thematic interpretation, he describes himself as an 'Afrocubist' and further describes his sculptures as bearing multiple expressional values which can be attributed to the multi-inspirational approach to his work. He further attributes the development of his type of sculptures to a noble calling or passion, augmented by a sense of mission that ties his identity to that of the individual sculpture. He treats his stone material with passion, confidence and humility

\section{The interpretative essence of the work}

Examining selected works by the sculptor, this paper delves into the interpretative essence of his work in terms of derivation of subject matter based on broad themes as well as general execution of each piece. As has already been observed, the development of sculpture can be viewed from two broad perspectives. Firstly, the celebrated African sculptural tradition where sculptural art was done for the purpose of serving the interest of the community, be it religious, secular or ceremonial. In each of these categories, specific and very purposeful types of sculptures were created in order to highlight important aspects of culture, traditions and belief systems. It has been noted that sculpture in the African sculptural tradition was not for the purpose of self-expression. Secondly, the more European oriented sculptural tradition which placed self-expression at the heart of the fundamental essence of sculpture, creating a major departure from the former. Sainz (2019) writes that:

Sculpture had a historical role to make real, in solid matter, respect for gods, imagined beasts, religious icons or special things or notable persons. However, in the modern era the role of sculpture, like most art, has changed to be more about exploring or expressing more secular concerns like individual expression on 
East African Journal of Arts and Social Sciences, Volume 2, Issue 1, 2020

Article DOI: https://doi.org/10.37284/eajass.2.1.218

issues such as highlighting aspects of the world or our place in it that we generally ignore or take for granted or don't realize the gravity of or beauty in.

In this regard, therefore, Momanyi's work can be interpreted as 'expressive' inspired by a variety of themes that touch on pertinent matters affecting society in Kenya, or what he calls 'topical issues'. McGlade (2018) states:

The importance of sculpture these days, like all art, is to shed new light on these human and world issues by making us think/feel and reflect, consider, empathize, enjoy and even perhaps prompting action through this manipulation of matter in three dimensions and time.

The need to delve into the interpretive essence of this work emanates from what generally has been seen to be the problem in viewing sculptural work in Kenya. There has been a tendency of audiences and the general public to view sculptural pieces generally in passing or merely from a superficial perspective; mainly just the artistic appearance or general composition or perhaps the beauty or texture of the material used, but not to dwell significantly on the essence of the subject matter beyond the appearance of the forms. Very often the audiences will touch and marvel at the tangible texture of the sculptural surface and comment about the posture or general composition, but seldom about its essence or critical assessment of its aesthetic value. In other dispensations or what one would call 'ideal circumstances', the audience often wishes to 'comprehend' the content of the work and thereby reach a conclusion whether there is a point of convergence or disagreement with the content as viewed and interrogated. This element of engagement between the audience and the sculptural content lends credence to the whole purpose of self-expression since by extension, even though the sculptor may not be physically present, it engages the sculptor's mind and intellect. In this regard, this self-expression hence becomes the catalyst for debate, irrespective of whether or not the viewer agrees with the sculptor's views, assertions or opinions.

However, one dilemma that has faced sculptors and other artists is the matter of what kind of audience views or should view artwork and whether such an audience is competent enough to do so. There has always been a view that members of the public may not necessarily have the fundamental training to be able to unravel the aesthetical essence of various works of art including sculptural work and ultimately understand its value. In comparing the audiences between the traditional African Artist and the contemporary African artist, Crowder (1978) observes:

Where the traditional artist was always clear who his audience would be and on what basis his work would be judged or criticized, the contemporary artist has no guaranteed audience and most of those who pretend to criticize his works do so on criteria that are frequently subjective and often not informed by a solid training in Art criticism and Art history (p 134) 


\section{1. 'Education for all'}

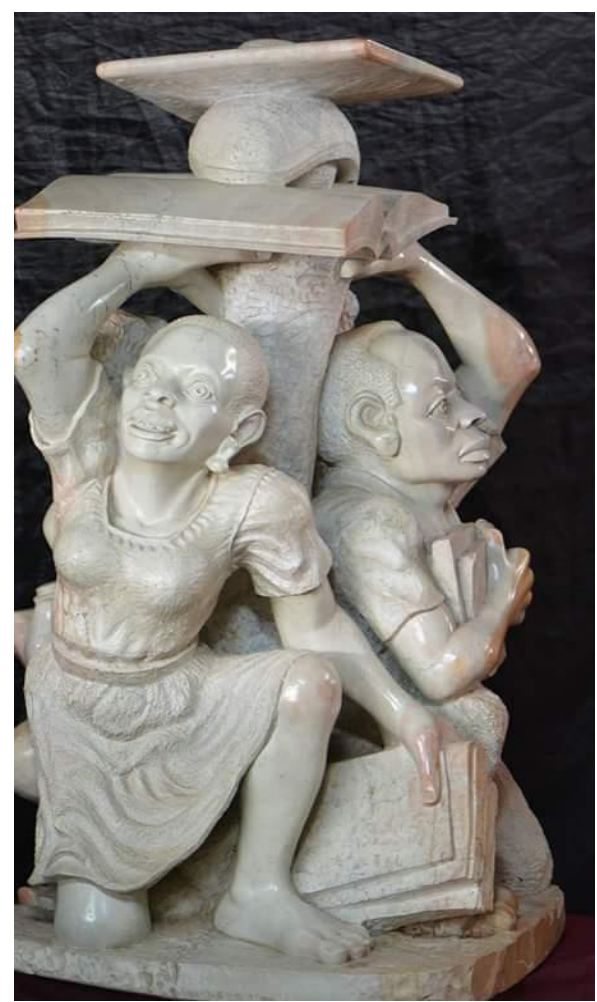

Plate 1a 'Education for all'

In the three-figure composition piece 'Education for all' (Plates 1a, 1b), the sculptor depicts the disparity between modern education symbolized by two young people holding books and lifting a degree cap as a mark of their achievement; and the traditional society, symbolized by an old woman holding a gourd ostensibly filled with milk and blood. The message is that the attainment of education in the modern context ultimately leads to limitless opportunities in livelihood symbolized by the books which, in turn, denote the power of knowledge. This deviates from the traditional set up where lack of modernity stifles opportunities and the potential for livelihood is therefore limited to traditional subsistence provisions, symbolized by the contents of the guard. At the same time, the sculpture highlights the triumph of the girl child in achieving equal measures of education enabling her to attain the capacity to enhance her opportunities for self-advancement. The three figures, the young



Plate 1b 'Education for all'

boy, the young girl and the old woman can be made out across plates $1 a$ and $1 b$

\section{Execution:}

In the sculpture 'Education for all' ( $89 \mathrm{~cm}$ height $\mathrm{x}$ $140 \mathrm{~cm}$ circumference) the sculptor uses a representational or figurative style since the human forms are clearly identifiable. Some parts of the forms, however, bear some element of stylization in terms of posture and body proportions, mainly for the purpose of utilizing compressed space in the holistic sculptural composition as well as expressive emphasis. Utilizing effective juxtaposition of masses and spaces, the sculptor skilfully carves out the forms into an interactive and dynamic composition probably influenced by a baroque style of using multiple figures. This is admirable bearing in mind that the composition is derived from a single body of rock. The sculptor also uses the natural smooth texture of the stone to 
his advantage particularly in depicting parts of the exposed face and body and creates textual effects in all other parts to depict cloth and ornamentation.

\section{2. 'Gesture of a loving mother'}

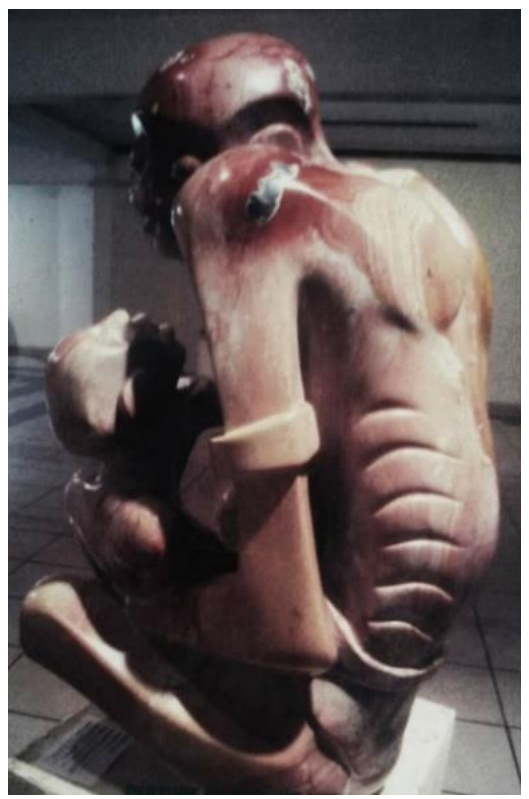

Plate 2a 'Gesture of a loving mother'

In the piece 'Gesture of a loving mother' (Plates 2a, $2 b)$ the sculptor demonstrates the loving and unique bond between a refugee mother and her child, where the mother still affords a wary smile in the midst of a hostile environment in order to reassure her child. This sculpture is derived from the plight of refugee mothers who despite uncertain and often volatile circumstances not only have to shield their children from constant danger but still have to bring them up in a semblance of normalcy, since the children may not comprehend the intricacies of conflict. The sculpture itself is based on the age-old theme of 'Mother and Child' and is an analogical reminder of the unbreakable bond that exists always between mother and Child.
The artist also uses his skill in creating folds on the cloth which are important in enhancing posture and gesture.

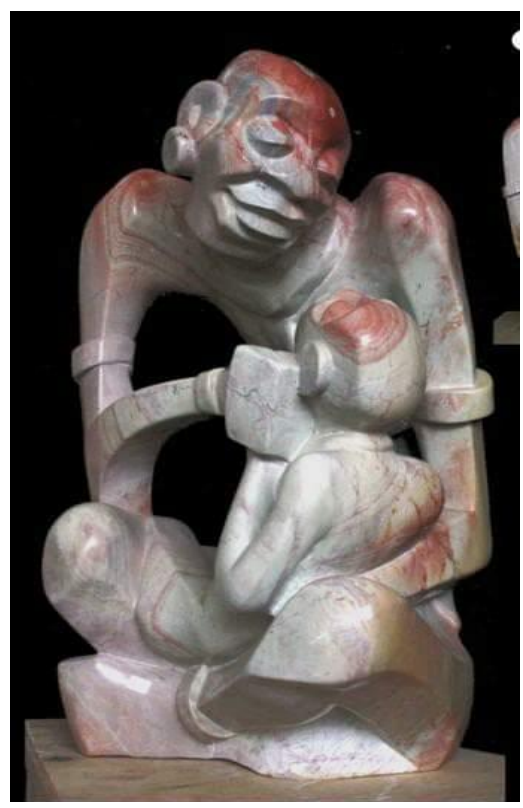

Plate $2 \mathrm{~b}$ ' 'Gesture of a loving mother'

\section{Execution:}

'Gesture of a loving mother' (71 cm height x 121 $\mathrm{cm}$ circumference) is presented in a figurative manner and is hence representational in nature. All aspects of the human form are apparent but combine heavily with stylization where all parts, seen particularly in the hands and feet are devoid of naturalistic detail. The sculptor also introduces sharp edges as seen in the hands, legs and face and combines these with rounded edges as seen in the shoulders and knees. The face bears exaggerated components intended to enhance the mother's loving expression. The sculpture is done in soapstone and is given a fine smooth finish which reveals the random natural colours of the stone as well as the beautiful grains which all serve as natural sculptural embellishments. 


\section{3. 'Screams of a broken gourd'}

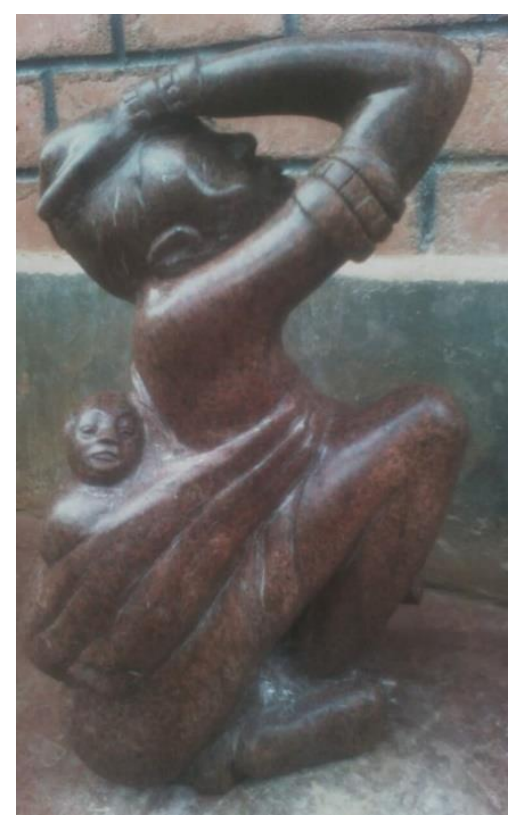

Plate 3a 'Screams of a broken gourd'

In 'Screams of a broken gourd' (Plates 3a, 3b) the sculptor narrates the story of an extremely distraught mother who accidentally breaks the gourd containing the only milk left for her hungry child. The sitting posture as well as the gesture of a hand lifted over the head, is a common reaction in such circumstances. The sculptor uses this pose to emphasize the agony and despair of the woman as well as the futility of her screams. By extension, this sculpture is a depiction of the agony of loss in all its manifestations, symbolized here by the broken gourd and the analogy of spilt milk, which once spilt cannot be retrieved.

\section{Execution:}

'Screams of a broken gourd' is a granite sculpture which is a combination of a figurative approach and stylistic emphasis through enlarged limbs. The sculptor uses a distinct, memorable gesture in his composition designed in this case, to express the futility of loss through a well thought out 'gesture of infinite agony' posture. The stone is well smoothed helping to bring out its grain and colour.

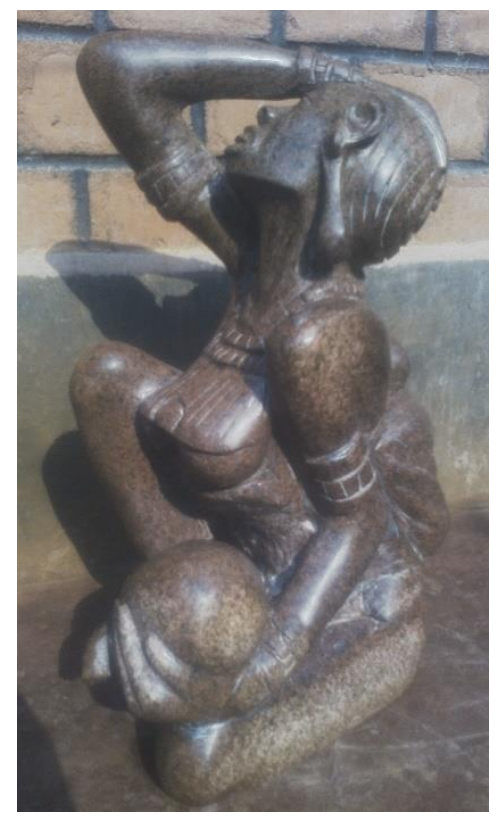

Plate 3b 'Screams of a broken gourd'

\section{4. 'African woman Buddha'}

This sculpture of an African Woman Buddha is an expressive amalgamation of African and Asian cultures. The work is, however, conceptualized to articulate the rich African cultural heritage in regard to the beautiful and intricate traditional attire worn by women in certain royal traditional ceremonies. The work on her attire is delicately executed featuring the influence of the large disclike necklace that hangs across the shoulder as part of the attire. There is also the depiction of ornamentation on the face, hands and waist. It is noticeable that her hair is intricately textured certainly imitating the legendary hair of Buddha which resembles knotted African hair. Her face is certainly African with clear African features. Dokosi (2015) observes that:

statues of the Buddha bore Africoid features namely thick lips, broad nose, long earlobes and was painted black plus the knotted hair also called cornrow which is popular with both male and female Africans. 


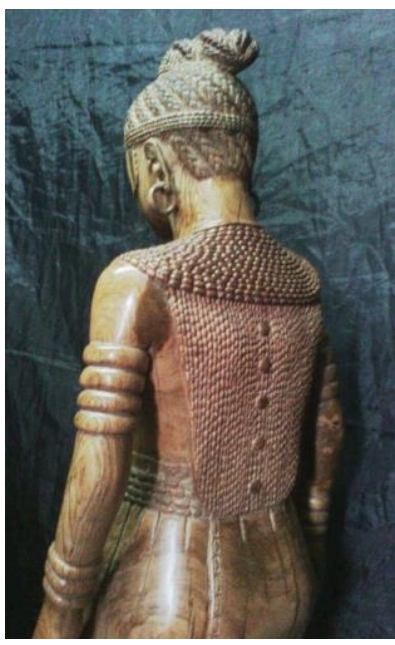

Plate 4a 'African woman Buddha'

To show the African connection to Asian sculptural culture, Dokosi further states that

Africoid (features) for our purpose refers to those native inhabitants of Asia whose phenotype closely resembles that of Africans.

According to the legend of the snail martyr's story, Buddha's coiled hair was created by snails that sought to protect his shaven head from the heat of the sun. They formed neat spiral shells that amounted to 108 coils over his scalp. It is these

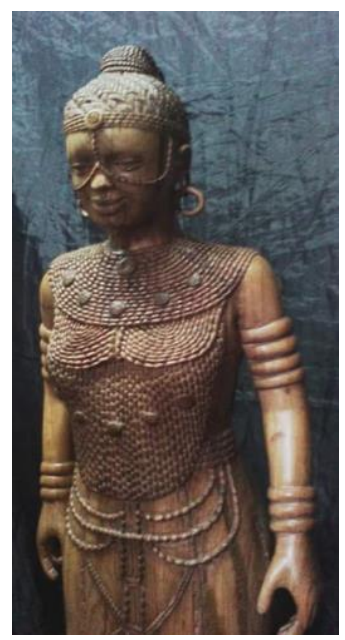

Plate 4b 'African woman Buddha'

Africoid or Negroid features that inspire African sculptors to want to incorporate them in their sculptures although the sculptures themselves may co-feature another complementary subject matter.

\section{Execution:}

"African woman Buddha" is executed in olive wood and it is a masterly depiction of textural details of attire. The wood itself is finely finished with either textured or a smoothed surface.

\section{5. 'Agony of Police brutality'}



Plate 5a

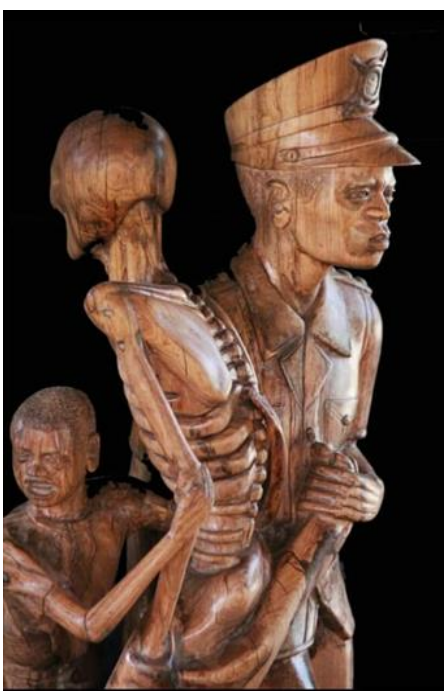

Plate $5 b$

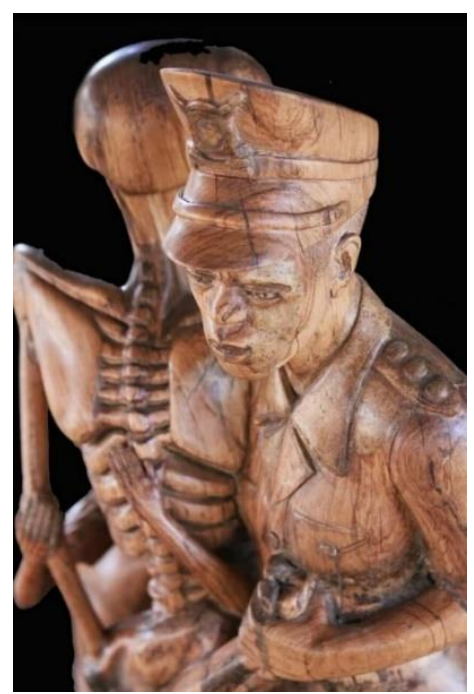

Plate 5c 
This sculpture which is a masterful combination of multi-figures is based on the theme of Police brutality. It is a powerful depiction of the agony of Police brutality and laments the overall injustice associated with extra-judicial killings or disappearances. This subject matter is still pertinent in Kenyan contemporary society where the police have constantly been accused of extra-judicial eliminations and disappearances where victims are neither accorded a chance to appear in court nor even charged with a specific criminal offence upon arrest. In some instances, victims are shot dead at the point of contact with the police or subsequently die in police custody. According to the 2017 Human Rights Report by Amnesty International, Kenya ranked top in Africa in cases of police shootings and killing of civilians.

The subsequent suffering of the families of the victims is vividly depicted through the grim and uncertain fate of the wife and young child (plate 5a) highlighting the sadness and despair of the woman holding a restless and suffering child. The posture of the woman is both figurative as it is profound; her head rested on her hand, her pained facial expression and the almost resigned manner in which she holds her equally stressed child.
In examining the other part of the sculpture, the agony of the son clinging desperately onto the skeleton (symbolizing the deceased father) and standing next to a stiff policeman who depicts the stiff culture of police brutality and insensitivity is very profound. The posture of the desperate boy and the expression on his face, as well as his embrace of the skeleton, are testimonies of his grief (plate 5b, 5e). The facial expression of the skeleton depicts the irreversible 'tragedy of the deed', the hand of death at the hands of the police that seals the fate of the victim of their brutality (plate $5 \mathrm{~d}$ ). It is quite telling that the composition shows the policeman holding a gun from the back view which alludes to the concept of the 'smoking gun' or the guiltiness of the police (plate 5d). The neat uniform and the posture depicting slight forward march depict the uncompromising nature of police as well as the general irony of police service (Plate $5 \mathrm{f}$ ). The holistic sculpture is interpretative of the grave point that the victims of police brutality are normal human beings with responsibilities like everybody else and their fate in the hands of the police bears direct consequence upon the livelihood of their families and dependents.

\section{'Agony of Police brutality'}

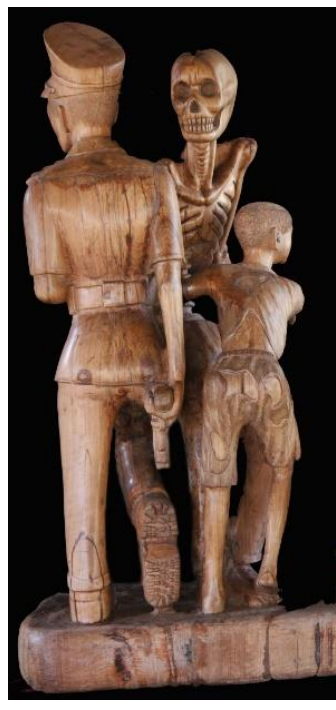

Plate 5d

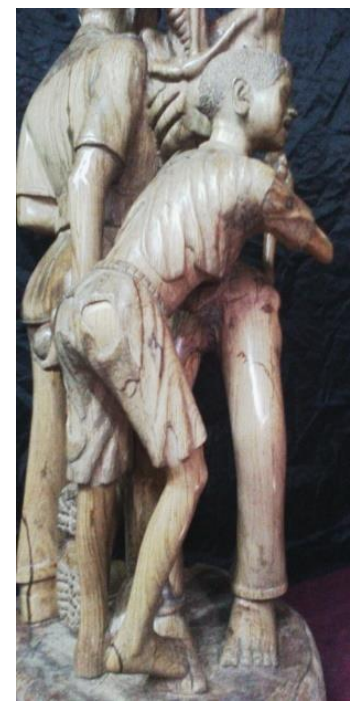

Plate 5e

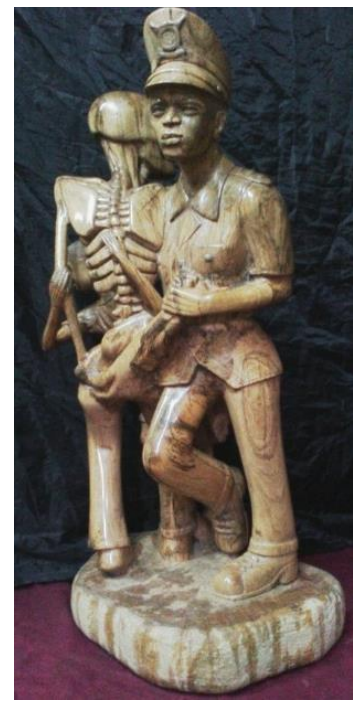

Plate $5 \mathrm{f}$ 
East African Journal of Arts and Social Sciences, Volume 2, Issue 1, 2020

Article DOI: https://doi.org/10.37284/eajass.2.1.218

\section{Execution}

The sculpture is executed in Olivewood and is a fine depiction of textural details and textural effects that follow the natural grain of the wood. The sculptor shows remarkable skill in manipulating the wood in order to highlight certain pertinent details and features that help underscore the subject matter such as the feeling of emotion in the woman's face and the unique but simple sitting body posture to show her despair. The baby with a slumped head can be described as a significant aspect of the entire sculptural composition because that alone underscores the extent of despair.

The execution of the sculpture itself can be described as figurative within the confines of sculptural limitations since the forms are well defined in terms of proportions, attire, facial expression, posture and action. The sculptor again borrows from the baroque style of using multiple figures that culminate in a very dynamic composition. This cluster of forms that are interrelated is intended to tell his story with each component representing an aspect of the unfolding drama. There is of course the deliberate insertion of the skeleton within the composition which introduces an interesting aspect of surrealism. The sculptor uses that to depict the fate of the victim of police brutality (Plate 5d). In what can be termed as 'the futility of interaction' between the naturalistic forms and the surreal skeleton, the sculptor underscores the tragedy of the moment as well as the irreversibility of the deed.

\section{6. 'Nabongo Mumia' Chess set carvings}

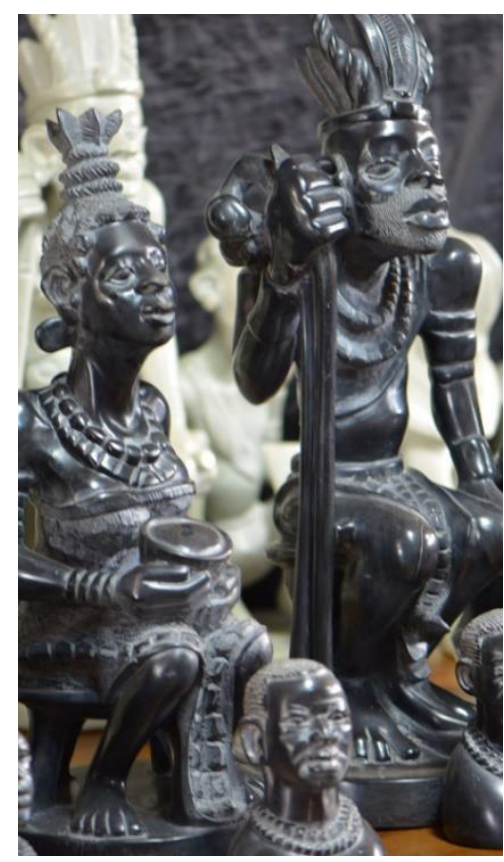

Plate 6a 'King and queen'

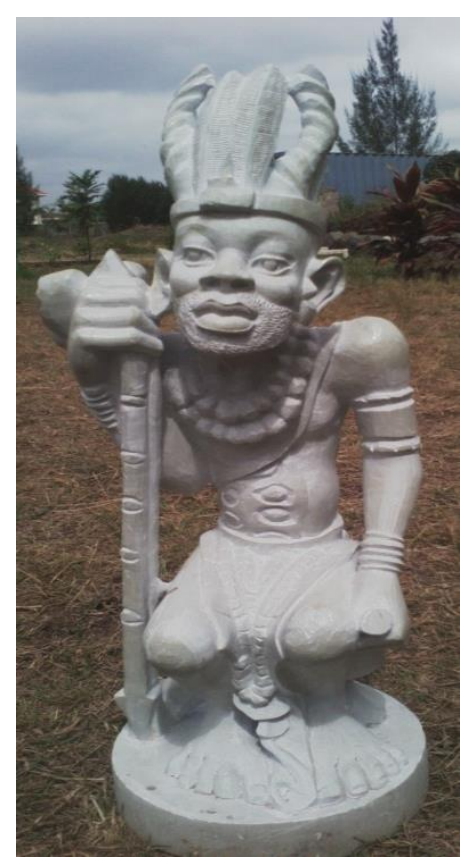

Plate 6b 'Nabongo Mumia

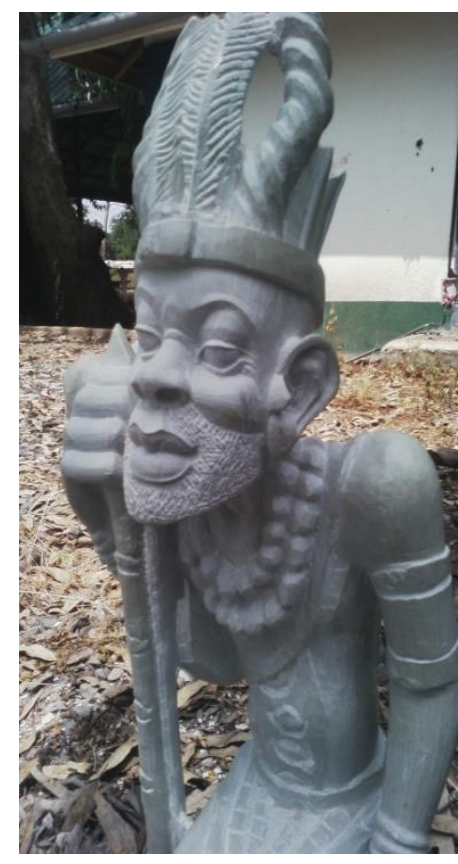

Plate 6c 'Detail of King'
This African chess set named Nabongo Mumia commemorates the life of Nabongo Mumia, King of the Wanga Kingdom of Western Kenya. The creation of this kind of sculptural work means that this genre can be used for commemorative, educative and cultural purposes through aspects of leisure and recreation; in this case, the game of Chess. As people engage the chess pieces, they study their individual and collective content.

Mumia, King of the Wanga and Paramount Chief of the greater western Kenya region was born 
between 1849 and 1852. He was a renowned peacemaker and was instrumental in encouraging trade routes though his Kingdom, greatly opening up his territory and subjects to thriving trade and social exposure. He became an ally of the British in Western Kenya which greatly consolidated his own power and helped him pursue an expansionist agenda that spread his influence throughout Western Kenya and beyond. He also used his ties with the British to introduce modern agriculture, schools, trade and transport through missionaries coming in from Uganda. Ochieng (1992) describes him as 'one of the greatest Kenyans that lived at the turn of the $20^{\text {th }}$ Century'. He died in 1949 aged around 92 years.

\section{Execution}

The chess pieces carved out in soapstone are representational combining elements of stylization and figurativism in execution, emphasizing parts of the body such as the head, hands and feet. The sculptor pays attention to various symbols of royal authority such as the royal stool, royal crown, ceremonial staff as well as aspects of the traditional regalia and ornamentation. All the pieces are intricately carved, smoothly finished and polished despite their small size and certainly tell a story of the King, including his Queen and their minders (Plates 6a, 6b, 6c).

\section{CONCLUSION}

From the foregoing a number of conclusions can be drawn:

1. That sculpture still remains a powerful avenue for self-expression. Self-expression itself can be viewed from two broad perspectives; one which is based on convectional imagery or imagery drawn from tangible occurrences, events, regular observations or the featuring of nature as it exists. Self-expression can also emanate from non-conventional imagery; particularly from the subconscious mind, dreams, fantasy or surrealistic dispensations. This paper focuses on the type of self-expression that is anchored on subject matter that touches on issues that are pertinent in Kenyan Society. In this context, it is evident that self-expression accords the artist the opportunity to express the content of the subject matter purely from his personal perspective, strengthening his own ability to communicate this perspective without any other patronizing view. This places the artist on a pedestal upon which he is able to construct a viable opinion of the matter at hand and subsequently disburse this opinion to his audience and the general public. The artist hence takes responsibility for his/her views and subsequently bears the obligation for their articulation.

2. That sculpture, in this regard, is viewed as a powerful artistic tool for public communication and education. While it becomes the artist's sole mandate for his/her self-expression, it is the public's obligation to comprehend and hence internalize the content of the subject matter. This interaction between artist and audience results in the interrogation of subject matter and hence the crystallization of the overall body of opinion of the pertinent issue at hand. Instances where a pertinent issue is better internalized results in a society that is better informed and therefore more enlightened.

3. That the use of 'narrative sculpture' to tell a specific story is effective in addressing some types of subject matter, particularly those that touch on pertinent social issues that the audience or the general public need to view, comprehend and dissect. The effectiveness of this type of sculpture can be captured by the use of an individual form which single-handedly depicts the story or a cluster of forms that inter-relate to complete the narrative.

4. That in execution, the masterly of use of materials and the exploitation of the natural qualities of the material in use such as natural textures and grains play a pivotal role in the 
overall appeal of the sculpture and helps the sculptor to apply emphasis on parts of the sculpture that aids in the articulation of subject matter.

5. That the use of a confluence of styles such as a figurative approach, with elements of naturalism and a degree of stylization can prove to be very helpful in helping the sculptor articulate a desired message and ultimately help mould the sculptor's personal style.

6. That individual passion not only for the execution of work and use of tools but also for the quest for knowledge and information through inquisitiveness is of critical importance in the formulation of the subject matter. This helps the sculptor to develop the impetus for the development of viable opinions that carry weight with the audience or viewers of the final product. In the interrogation of the work, these opinion(s) are respected since they are well researched and subsequently rationalized.

7. That 'self-expression' is not necessarily for the 'self'. While it is quite common for sculptors and other artists to create work that expresses their deep feelings and emotions and hence bears a unique stamp of individual subjectivity, or even individuality, all creative work is ultimately destined to be viewed by a given audience or the public at some point in time. Once the artist has expressed his emotions and a measurable account of self-aggrandizement has manifested itself, then what becomes of the work? This paper posits that all sculptural work or any other work that is of significant creative value should, to a large extent, be of 'Universal expressive Essence'. This means that even though the expression of feelings and emotions is in itself subjective and hence motivated by the sense of 'self', its essence is not; since its creative synergy does not flow inwards but outwards towards all other people; including those that might share similar experiential phenomena.
The subsequent work or the holistic content of creativity becomes important for its imaginative, aesthetic, emotional or even intellectual value, as the case may be. It, hence, becomes pertinent and useful to others as all these factors are extracted and consumed by other people.

\section{REFERENCES}

Beier, U. (1961). Contemporary Nigerian Art. Nigeria Magazine (Lagos), No 68

Crowder, M. (1978). The Contemporary Nigerian Artist: His Patrons, His Audience and His Critics Présence Africaine Nouvelle série, No. 105/106, pp. 130-145

Dokosi, M. E. (2019, October 15). Unravelling the background to the Africoid features and knotted hair of the Buddha. Pan-African weekend. Retrieved from https://face2faceafrica.com/article/unravelingthe-background-to-the-africoid-features-andknotted-hair-of-the-buddha

Fagg, E. (1963). Nigerian Images. Cambridge University Press, London

Friendenwald-Fishman, E. (2011, May 26). No art? No social change. No innovation economy. Stanford Social Innovation Review. Retrieved from https://ssir.org/articles/entry/no_art_no_social _change._no_innovation_economy\#

Mbahi, A. A. (2003). Trends of Art Education in Nigeria. Journal of the College of Art, 1(7), 3340.

McGlade (2018). What is the importance of sculptures in this modern world?. Retrieved from https://www.quora.com/What-is-theimportance-of-sculptures-in-this-modernworld

Ochieng W, R., \& Kenyanchui, S. (1992). Nabongo Mumia Heinemann, Nairobi. 
East African Journal of Arts and Social Sciences, Volume 2, Issue 1, 2020

Article DOI: https://doi.org/10.37284/eajass.2.1.218

Peligah, Y. S (2003). Spirituality in Ghanaian Art Education: influence of conceptual paradigms on classroom practices Journal of the College of Art. Volume 1, No.7 pp 10-16

Sainz, R (2019). Roberto Sainz. Retrieved from https://www.quora.com/profile/Roberto-Sainz-

2 